\title{
The Early Life of a Peptide Cation-Radical. Ground and Excited-State Trajectories of Electron-Based Peptide Dissociations During the First 330 Femtoseconds
}

\author{
Christopher L. Moss, Wenkel Liang, Xiaosong Li, František Tureček
}

Department of Chemistry, University of Washington, Bagley Hall, Box 351700, Seattle, WA, USA

\begin{abstract}
We report a new approach to investigating the mechanisms of fast peptide cation-radical dissociations based on an analysis of time-resolved reaction progress by Ehrenfest dynamics, as applied to an Ala-Arg cation-radical model system. Calculations of stationary points on the ground electronic state that were carried out with effective $\operatorname{CCSD}(T) / 6-311++\mathrm{G}(3 \mathrm{df}, 2 \mathrm{p})$ could not explain the experimental branching ratios for loss of a hydrogen atom, ammonia, and $\mathrm{N}-\mathrm{C}_{\alpha}$ bond dissociation in $(\mathrm{AR}+2 \mathrm{H})^{+\bullet}$. The Ehrenfest dynamics results indicate that the ground and lowlying excited electronic states of $(\mathrm{AR}+2 \mathrm{H})^{+\bullet}$ follow different reaction courses in the first 330 femtoseconds after electron attachment. The ground $(\boldsymbol{X})$ state undergoes competing loss of $\mathrm{N}$ terminal ammonia and isomerization to an aminoketyl radical intermediate that depend on the vibrational energy of the charge-reduced ion. The $\boldsymbol{A}$ and $\boldsymbol{B}$ excited states involve electron capture in the Arg guanidine and carboxyl groups and are non-reactive on the short time scale. The $\boldsymbol{C}$ state is dissociative and progresses to a fast loss of an $\mathrm{H}$ atom from the Arg guanidine group. Analogous results were obtained by using the B3LYP and CAM-B3LYP density functionals for the excited state dynamics and including the universal M06-2X functional for ground electronic state calculations. The results of this Ehrenfest dynamics study indicate that reaction pathway branching into the various dissociation channels occurs in the early stages of electron attachment and is primarily determined by the electronic states being accessed. This represents a new paradigm for the discussion of peptide dissociations in electron based methods of mass spectrometry.
\end{abstract}

Key words: Electron-transfer dissociation, Ehrenfest quantum dynamics, Peptide ions

\section{Introduction}

Charge reduction of gas-phase peptide cations by electron attachment forms cation-radicals that have

Electronic supplementary material The online version of this article (doi:10.1007/s13361-011-0283-9) contains supplementary material, which is available to authorized users.

Correspondence to: Xiaosong Li; e-mail: 1i@chem.washington.edu, František Tureček; e-mail: turecek@chem.washington.edu been of keen interest because of their unusual reactivity. Electron capture and transfer trigger extensive dissociations of charge-reduced species by loss of hydrogen atoms, ammonia, side-chain groups, and also by cleavages of disulfide and peptide backbone bonds [1]. The experimental methods utilizing this phenomenon are electron transfer dissociation (ETD) [2] and electron capture dissociation (ECD) mass spectrometry [3], which are collectively referred to as ExD [1]. Peptide bond cleavages occur mainly, although not exclusively, between the amide nitrogens and 
adjacent $\mathrm{C}_{\alpha}$ atoms $\left(\mathrm{N}-\mathrm{C}_{\alpha}\right.$ cleavage for short) to form series of $\mathrm{N}$-terminal $(c)$ and $\mathrm{C}$-terminal $(z)$ fragment ions that are utilized for peptide and protein sequencing by mass spectrometry $[1,4]$. The nature of $\mathrm{ExD}$ has been investigated by experiment and theory with aims that ranged from statistical evaluation of the observed dissociations over large ad hoc sets of peptide ions [5, 6] to analysis of fragmentations of selected model peptide ions to formulate plausible mechanisms [7-18].

An early suggestion of an $\mathrm{N}-\mathrm{C}_{\alpha}$ cleavage mechanism postulated that electron capture proceeds through a highlying Rydberg state that undergoes crossing to a repulsive $\sigma^{*}$ state involving the $\mathrm{N}-\mathrm{C}_{\alpha}$ bond [19]. One of the motivations for this mechanism was that it avoided internal vibrational relaxation in the charge-reduced intermediates, which was considered to be prohibitive to allow for dissociation of large peptide and protein ions. However, an investigation of potential energy surfaces for several peptide radicals and cation-radicals indicated that electron attachment had a tremendous effect on lowering the transition state (TS) energies for $\mathrm{N}-\mathrm{C}_{\alpha}$ bond cleavages [20]. The TS energies calculated for several peptide radicals and cation-radicals [21] were as a rule $<50 \mathrm{~kJ} \mathrm{~mol}^{-1}$ and were comparable to the barriers for peptide refolding in the gas phase [22]. Experimental [23, 24] and computational [25] studies have indicated that ExD were susceptible to conformational effects, unlike collision-induced dissociations of peptide ions which do not show stereochemical effects. The calculated rate constants for $\mathrm{N}-\mathrm{C}_{\alpha}$ bond cleavages in peptide cation-radicals were shown to be $\sim 10^{5} \mathrm{~s}^{-1}$ even at $298 \mathrm{~K}$ [26]. This indicated that ground-state peptide cation-radicals had intrinsic reactivity for $\mathrm{N}-\mathrm{C}_{\alpha}$ bond cleavage.

Regarding excited states, Simons and coworkers investigated electronic states formed by adding an electron to a neutral Ala-Ala molecule that was furnished with a remote point charge [27]. They found a crossing of the selected $\sigma^{*}$ excited state with the ground state of the peptide at an $\mathrm{N}-\mathrm{C}_{\alpha}$ distance of about 2.0 A. However, the excited state was $10 \mathrm{eV}$ above the ground state in the initial molecular geometry, which was substantially out of the range of electron binding energies in peptide cation-radicals. A concurrent analysis of the electronic properties of amide groups in the presence of remote charge carriers, such as ammonium and guanidinium indicated that (1) chargeassisted electron attachment to the amide group produced a bound excited state represented by a $\pi^{*}$ orbital, and (2) the pertinent amide anion-radical had sufficient basicity to abstract a proton from the protonated ammonium or guanidinium group such as those in lysine and arginine residues to form a reactive aminoketyl radical [28]. This led to the formulation of the Utah-Washington mechanism of ExD (see reference [29] for details). Simons and coworkers have further focused on investigating the interactions and electron transfer between ammonium Rydberg and disulfide $\sigma^{*}$ orbitals and have put forth rules that correlated the electron transfer efficiency with the distance of the interacting groups [30-33].
The energetics of $\mathrm{N}-\mathrm{C}_{\alpha}$ bond dissociations in peptide cation-radicals indicate that backbone fragmentations are possible in the ground electronic states. Consequently, most research has hitherto addressed backbone dissociations occurring after the electron has decayed to the ground electronic state of the peptide cation radical. The ultimate goal of theoretical kinetic analysis is to provide relative rate constants for competitive dissociations that would explain or predict the experimental branching ratios. However, a recent detailed kinetic analysis of backbone dissociations of a pentapeptide cation-radical has concluded that these did not occur competitively on the ground-state potential energy surface, but rather involved different electronic states [34]. Likewise, ECD of peptide ions modified with fixed-charge tags was interpreted by involving excited electronic states to explain the observed dissociations [35].

In this work, we analyze the ground and excited electronic states of an experimentally studied peptide cation radical to propose that not only is the electron captured in an orbital corresponding to an excited state, but that subsequent dissociations occur on excited state potential energy surfaces (PESs) before the electron reaches the ground state. Migration of the electron to a reactive site, which is a nonadiabatic process, can be difficult to characterize using Hartree-Fock self-consistent field computational methods or linear response methods, such as time-dependent density functional theory (TD-DFT) [36]. Advances in computational power and algorithm improvements have made it possible to perform Ehrenfest direct dynamics calculations [37-39] on systems of experimental interest. Ehrenfest dynamics allows us to follow the ab initio, non-adiabatic trajectory of systems on a mean potential energy surface (PES) within a coherent electronic wave function framework. This approach is particularly useful for systems that have electronic states that are closely spaced in energy, which is characteristic of peptide cation-radicals [29, 34]. Ehrenfest dynamics calculations allow one to explore regions of the excited state potential energy surface where the electron and nuclear motions couple, resulting in nonadiabatic transitions between closely spaced electronic states [37]. This approach is different from Born-Oppenheimer dynamics, which examines adiabatic trajectories on a selected electronic state, as applied by Uggerud and coworkers to study $\mathrm{H}$ atom capture by the amide group in a smaller neutral amide system [40].

The peptide system we chose to study is the cationradical $(\mathrm{AR}+2 \mathrm{H})^{+\bullet}$ prepared by electron attachment to doubly protonated Ala-Arg, $(\mathrm{AR}+2 \mathrm{H})^{2+}$. A previous experimental study [41] established that femtosecond collisional electron transfer from a $\mathrm{Cs}$ atom to $(\mathrm{AR}+$ $2 \mathrm{H})^{2+}$ resulted in complete dissociation of $(\mathrm{AR}+2 \mathrm{H})^{+\bullet}$ within $5 \mu \mathrm{s}$. The main dissociations were loss of an $\mathrm{H}$ atom $(25 \%)$, ammonia (43\%), and cleavage of the $\mathrm{N}-\mathrm{C}_{\alpha}$ bond $(12 \%)$ forming an $\alpha$-deaminated arginine cationradical (C-terminal $z_{1}$ fragment ion, Scheme 1). Experimental studies using fast ion and neutral beams have 

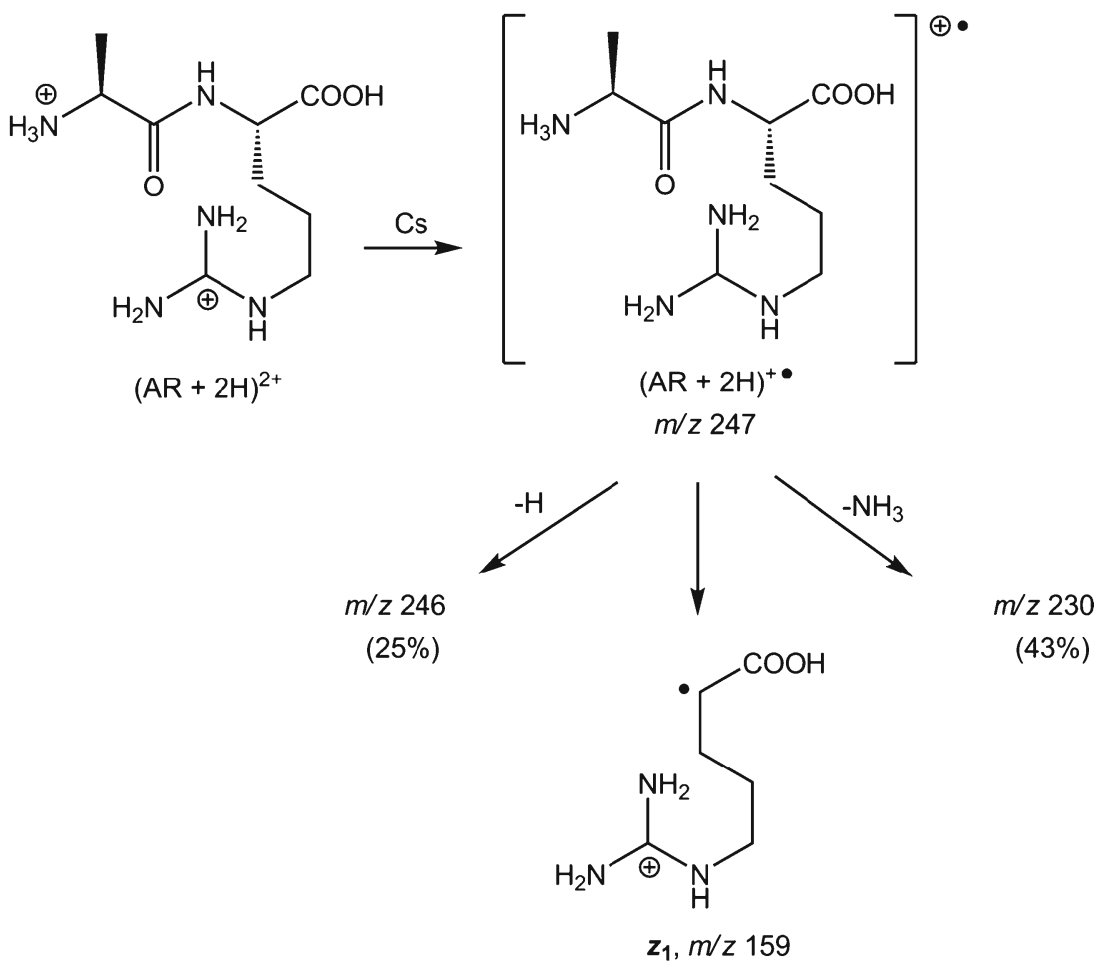

$(12 \%)$

Scheme 1. Main dissociations of $(\mathrm{AR}+2 \mathrm{H})^{2+}$ upon electron transfer from $\mathrm{Cs}$ atoms

been able to investigate dissociations and isomerizations of small peptide radicals within 100-200 ns of their formation [41]. However, fast reactions occurring on a shorter time scale could not be resolved by experiments, and thus the early development of the peptide radical system could not be examined. We employ Ehrenfest dynamics to investigate the time course of processes occurring on potential energy surfaces of different electronic states of the $(\mathrm{AR}+2 \mathrm{H})^{+\bullet}$ cation-radical within the first 330 femtoseconds of electron attachment to (AR $+2 \mathrm{H})^{2+}$. We also provide a detailed analysis of stationary points on the potential energy surface of the ground electronic state using a high level of ab initio theory.

\section{Methods}

All calculations were performed using the Gaussian 09 program suite [42] run on parallel 8-processor nodes. Molecular dynamics (MD) search of the conformational space for the $(\mathrm{AR}+2 \mathrm{H})^{2+}$ precursor dication was performed using a previously reported scheme [43]. This consists of replica exchange molecular dynamics (REMD) [44] calculations on the peptide ion. MD calculations were run for $10 \mathrm{~ns}$ with a step size of $1 \mathrm{fs}$ with eight temperature replicas from 300 to $800 \mathrm{~K}$. One thousand structures from each replica were selected at regular intervals for a total of 8000 initial candidate structures. Each candidate structure was then optimized at the PM6 level [45]. The PM6 optimized structures were then analyzed for potential hydrogen bonds. Structures with the same hydrogen bonds were grouped together, and the lowest energy structure from each group was taken to form a new list of candidate structures. The single point energy for each candidate structure was calculated at the B3LYP/6-31+G(d,p) level of theory [46, 47], the structures from each sequence with the lowest energy were re-optimized at the same level, and the local minima were confirmed with frequency calculations.

Regarding cation-radicals, stationary points for local energy minima and first-order saddle points on the ground electronic states were obtained with B3LYP, its Coulombattenuating version CAM-B3LYP [48], and the universal M06-2X functional [49], all with the $6-31+G(d, p)$ basis set. Single-point energies were obtained with these functionals, as well as with Moller-Plesset [MP2(frozen core)] calculations [50] using the $6-311++\mathrm{G}(2 \mathrm{~d}, \mathrm{p})$ and $6-311++\mathrm{G}$ ( $3 \mathrm{df}, 2 \mathrm{p})$ basis sets. At our highest level of theory, coupled cluster calculations [51] were performed with single, double, and disconnected triple excitations $(\operatorname{CCSD}(\mathrm{T}))$ [52] and the $6-31+\mathrm{G}(\mathrm{d}, \mathrm{p})$ basis set and expanded to effective CCSD/6$311++\mathrm{G}(3 \mathrm{df}, 2 \mathrm{p})$ using the standard linear formula, $E$ [CCSD $(\mathrm{T}) / 6-311++\mathrm{G}(3 \mathrm{df}, 2 \mathrm{p})] \approx \mathrm{E}[\mathrm{CCSD}(\mathrm{T}) / 6-31+\mathrm{G}(\mathrm{d}, \mathrm{p})]+\mathrm{E}$ [PMP2/6-311++G(3df,2p)] - E[PMP2/6-31+G(d,p)] [53].

Ehrenfest dynamics was implemented as a real-time TDDFT method to investigate the PES for various electronic states [36-38]. The TD-DFT Ehrenfest dynamics is integrat- 
ed with a triple-split operator (Figure 1). The first operator propagates the electronic TD-DFT equation in matrix form,

$$
i \frac{d \mathrm{P}}{d t}=[\mathrm{K}, \mathrm{P}]
$$

where $\mathrm{P}$ and $\mathrm{K}$ are the density and Kohn-Sham matrices, respectively, in an orthonormal basis. A modified midpoint unitary transformation (MMUT) algorithm with a time step of $\Delta t_{\mathrm{e}}$ is implemented to integrate Equation (1) to give Equation (2),

$$
\mathrm{P}\left(t_{k+1}\right)=\mathrm{U}\left(t_{k}\right) \cdot \mathrm{P}\left(t_{k-1}\right) \cdot \mathrm{U}\left(t_{k}\right)
$$

where the propagator $U$ is constructed from the eigenvalue and the eigenvectors of the Kohn-Sham matrix as (Equations 3 and 4)

$$
\begin{gathered}
\mathrm{C}\left(t_{k}\right) \cdot \mathrm{K}\left(t_{k}\right) \cdot \mathrm{C}\left(t_{k}\right)=\varepsilon\left(t_{k}\right) \\
\mathrm{U}\left(t_{k}\right)=\exp \left[i \cdot 2 \Delta t_{e} \cdot \mathrm{K}\left(t_{k}\right)\right] \\
=\mathrm{C}\left(t_{k}\right) \cdot \exp \left[i \cdot 2 \Delta t_{e} \cdot \varepsilon\left(t_{k}\right)\right] \cdot \mathrm{C}\left(t_{k}\right)
\end{gathered}
$$

The second operator propagates nuclear degrees of freedom using a velocity-Verlet algorithm with a time step of $\Delta t_{\mathrm{N}}$. A third propagator couples electronic and nuclear degrees of freedom by recomputing the TD-DFT Hamiltonian every $\Delta t_{\mathrm{Ne}}$ time step. The overall time evolution of the TD-DFT Ehrenfest dynamics is given by $\Delta t_{\mathrm{N}}=n \Delta t_{\mathrm{Ne}}$ and $\Delta t_{\mathrm{Ne}}=m \Delta t_{\mathrm{e}}$.

The dynamics calculations require initial nuclear coordinates and velocity vectors for $(\mathrm{AR}+2 \mathrm{H})^{+\bullet}$, which are identical to those of vertically reduced $(\mathrm{AR}+2 \mathrm{H})^{2+}$. The vectors were generated from molecular dynamics (MD) using NAMD [54] and the CHARMM [55] set of force-

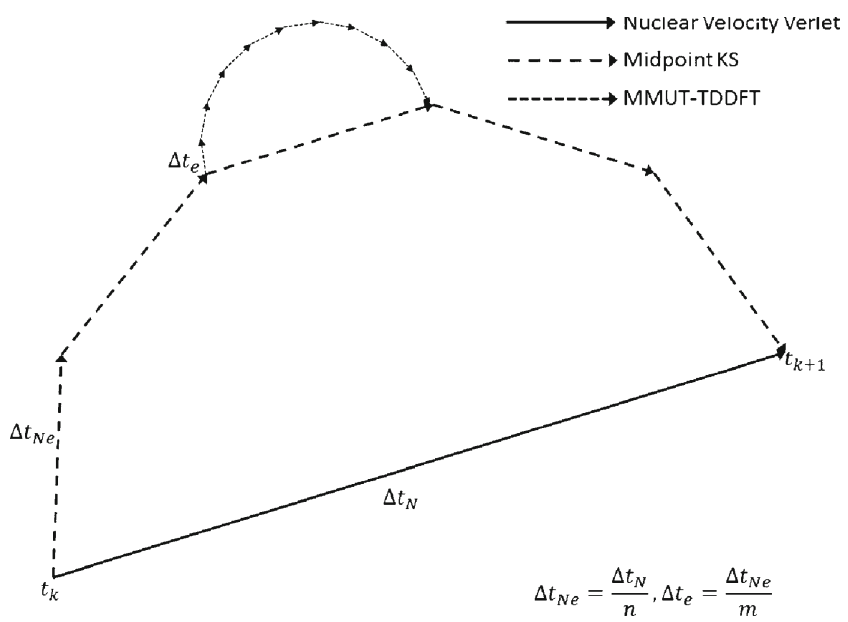

Figure 1. Graphic representation of propagation steps for electronic wave function and nuclear coordinates in the Ehrenfest dynamics run fields. A simulation was run of $(\mathrm{AR}+2 \mathrm{H})^{2+}$ in vacuum at $300 \mathrm{~K}$ for $5 \mathrm{ps}$ with a time step of $2 \mathrm{fs}$. Due to the small size of this system, equilibrium conditions were quickly reached and the Cartesian coordinates and velocity for each atom were averaged over the MD run. Under these conditions, the ion had an internal kinetic energy of ca. $108 \mathrm{~kJ} \mathrm{~mol}^{-1}$; when treated by the equipartition theorem, this corresponds to the total vibrational kinetic energy calculated at $300 \mathrm{~K}$. Note, however, that the equipartition theorem is known to overestimate molecular enthalpies [56]. When treated by standard statistical thermodynamics, the $(\mathrm{AR}+2 \mathrm{H})^{2+}$ ion is calculated to acquire a $108 \mathrm{~kJ} \mathrm{~mol}^{-1}$ rovibrational enthalpy at $520 \mathrm{~K}$. The averaged atomic coordinates were used to calculate the electronic density in the vertically reduced ion, and the averaged velocities were used as the initial conditions for the Ehrenfest dynamics calculations. While the resulting initial coordinates are not identical with the optimized ground state structure, the character of the molecular orbitals of interest is comparable to those from the stationary point calculations (Figure 2).

The initial SOMO electron density of the vertically reduced ion was generated by $\mathrm{B} 3 \mathrm{LYP} / 6-31+\mathrm{G}(\mathrm{d})$ for the coordinates obtained from MD. The first three excited states from linear response TD-DFT [35] were used to determine the LUMO $(0.060 \mathrm{eV}), \mathrm{LUMO}+1(0.18 \mathrm{eV})$, and LUMO + 2 $(0.52 \mathrm{eV})$ electron densities. The molecular orbital populations of the states of interest were selected and saved using the Population $=$ SaveNTO keyword in Gaussian 09. Because of the enormous computational demands of these trajectory calculations $(16,500$ spin-unrestricted DFT calculations per trajectory), we ran a single trajectory for each electronic or vibrational state. In addition, we used the same procedure to run Ehrenfest dynamics calculations with the CAM-B3LYP functional and the 4-31G(d) basis set to evaluate the effect of long range interactions in the ground and excited electronic states.

Ehrenfest dynamics calculations with B3LYP were carried out to $330 \mathrm{fs}$. The CAM-B3LYP dynamics calculations were run for 100 fs. Within the framework of dynamics step-size control, the average velocity Verlet time step was $0.1 \mathrm{fs}$. Within this time step, five steps of midpoint Kohn-Sham and 50 steps of modified midpoint unitary transformation (MMUT) TD-DFT propagators were used. Each trajectory consisted of 16,500 DFT calculations. All atoms were allowed to be fully dynamic. The total energy of the system was conserved to within $2.94 \times 10^{-4} \mathrm{eV}$.

\section{Results and Discussion}

\section{Electron Attachment and Electronic States}

Attaching an electron to the peptide dication in its equilibrium geometry is equivalent to a vertical electron transfer from the dication to the cation-radical potential energy surface (PES), as realized in collisional electron transfer 

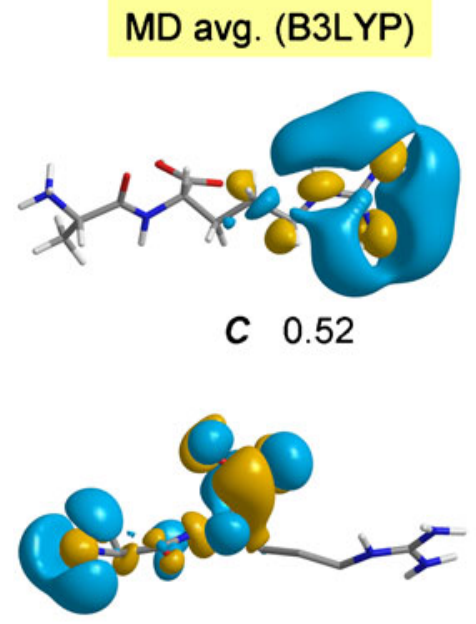

B 0.18

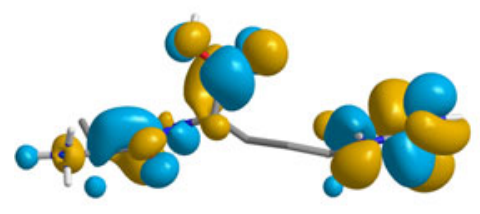

A 0.06

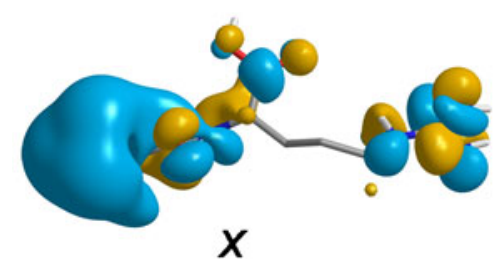

MD avg. (cam-B3LYP)

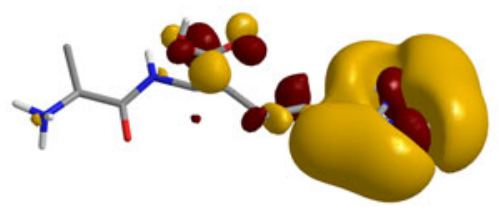

C 0.79

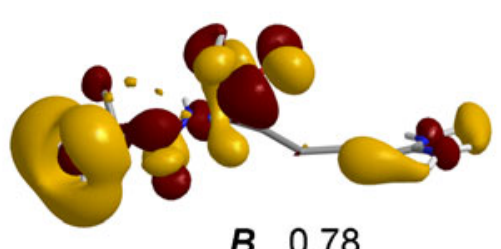

B 0.78

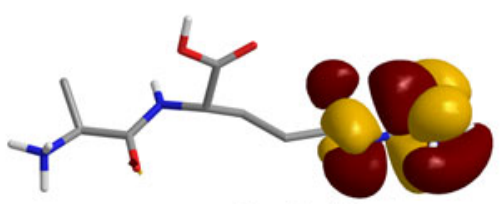

A 0.08

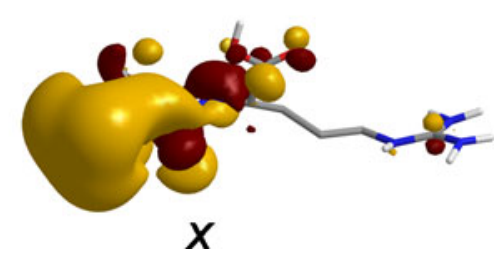

Figure 2. Molecular orbitals representing the electronic states after vertical electron attachment to $(A R+2 H)^{2+}$ with averaged MD geometry. The excitation energies are in electron volts

experiments [57]. This initial point, which can be a Rydberg state that crosses to a lower-lying valence state [31], lies on a multidimensional slope of the cation-radical PES. The electronic states at this point and the corresponding wave functions were calculated for $(\mathrm{AR}+2 \mathrm{H})^{+\bullet}$ with density functional theory using the B3LYP [46] and CAM-B3LYP [48] hybrid density functionals with the 6-31G(d) basis set. We first obtained the electronic states for $(\mathrm{AR}+2 \mathrm{H})^{+\bullet}$ at the MD geometry that was used as a starting point for the Ehrenfest dynamics calculations.

The B3LYP and CAM-B3LYP density functionals gave very similar manifolds for the low electronic states (Figure 2). The ground $(X)$ state wave functions were combinations of the ammonium 3 s-Rydberg orbital with amide and carboxyl $\pi^{*}$ orbitals. The $A$ states (denoted as LUMO) were closely spaced with the $X$ states by both B3LYP and CAM-B3LYP and consisted mainly of guanidinium $\pi^{*}$ orbitals. The $B$ states (LUMO +1 ) were combinations of ammonium $3 \mathrm{~s}$ and carboxyl $\pi^{*}$ orbitals. The $\boldsymbol{C}$ states (LUMO +2$)$ mainly consisted of guanidinium $\sigma^{*}$ orbitals (Figure 2). The B3LYP wave functions showed a somewhat greater extent of delocalization than did the CAM-
B3LYP ones; however, the main features of the electronic states and spin densities were very similar for both sets of data.

We also obtained excited electronic states with B3LYP, CAM-B3LYP, and M06-2X TD-DFT calculations and the larger $6-311++\mathrm{G}(2 \mathrm{~d}, \mathrm{p})$ basis set for vertical electron attachment to the fully B3LYP, CAM-B3LYP, and M06-2X optimized precursor dication structures. Again, the electronic states gave very similar excitation energies for all three density functionals, and consisted of the closely spaced ground state $(X)$ and excited states $A, \Delta \mathrm{E}=0.07-0.09 \mathrm{eV}, B$, $\Delta \mathrm{E}=0.16-0.19 \mathrm{eV}$ and $C, \Delta \mathrm{E}=0.52-0.62 \mathrm{eV}$ (Figure 3). The DFT methods differed in wave function nodality for these electronic states and also in the extent of electron delocalization in the $X$ state which was greatest for B3LYP and lowest for M06-2X (Figure 3) [58]. However, the wave functions from CAM-B3LYP and M06-2X calculations were substantially delocalized in the excited states, as illustrated by the $A$ state from cam-B3LYP and the $B$ state from M06$2 \mathrm{X}$ (Figure 3). The SOMO orbital of the $\boldsymbol{X}$ state contained contributions from the ammonium $3 \mathrm{~s}$-Rydberg, and the $\pi^{*}$ systems of the amide and arginine guanidinium groups. The 


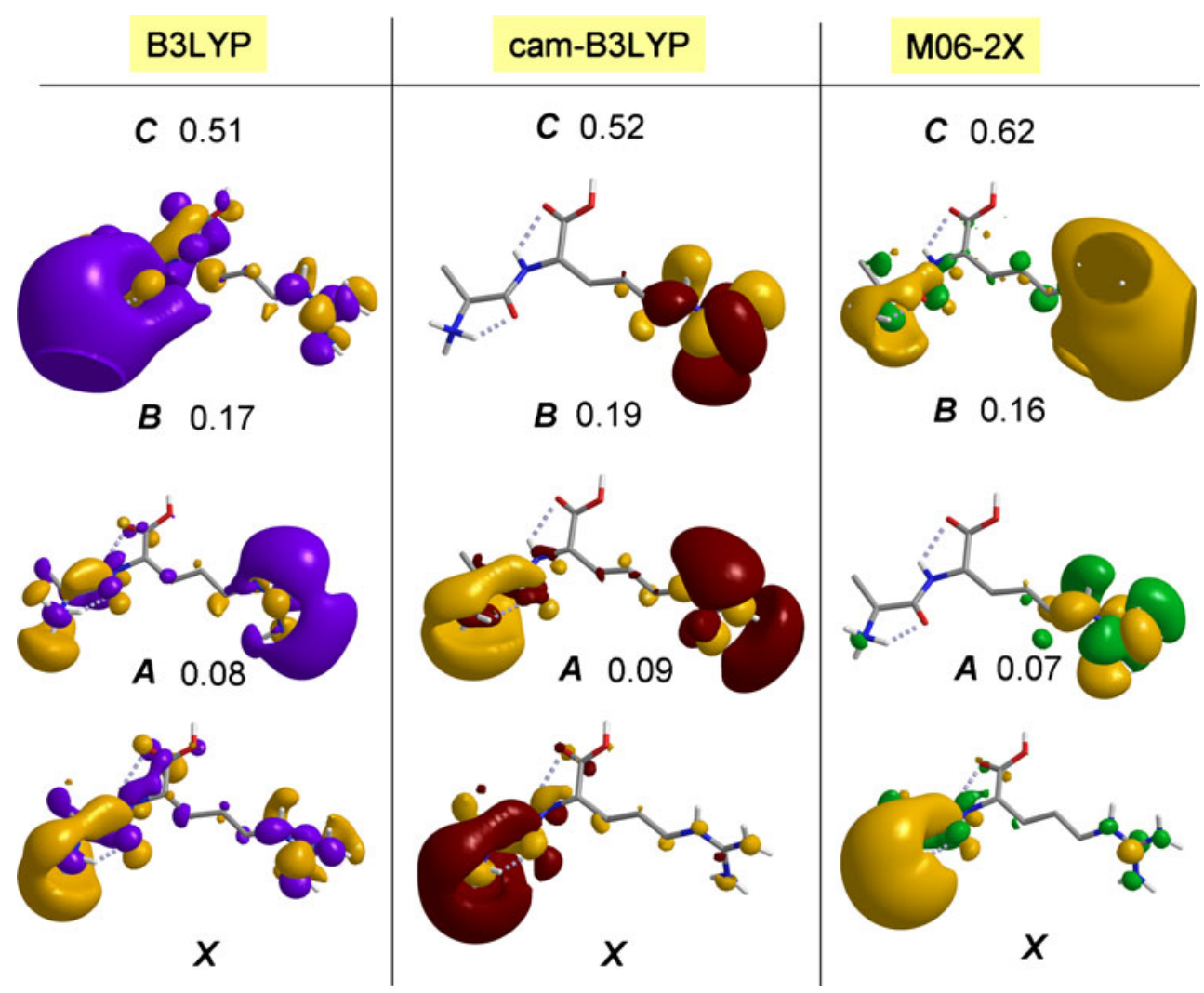

Figure 3. Molecular orbitals representing the electronic states in $(\mathrm{AR}+2 \mathrm{H})^{+\bullet}$. The first three columns from left show fully optimized structures. The rightmost column shows the averaged structure from the MD conformational search. The excited state energies and wave functions are from TD-DFT calculations with the 6-311++G(2d,p) basis set

next orbital describing the $A$ state, called here LUMO, had the greatest spin density in the guanidinium $\pi^{*}$ system. The LUMO +1 orbital of the $B$ state had the spin density on one of the terminal groups, depending on the DFT method. The LUMO +2 of the $C$ state was also concentrated within the arginine guanidinium group, but it had a $\sigma^{*}$ nodality instead of a $\pi^{*}$ one in the other molecular orbitals. We first describe the properties of the ground-state potential energy surface along the coordinates pertinent for the main dissociations by loss of $\mathrm{H}, \mathrm{NH}_{3}$, and $\mathrm{N}-\mathrm{C}_{\alpha}$ bond cleavage.

\section{Energetics of $(\mathrm{AR}+2 \mathrm{H})^{+\bullet}$ Cation-Radicals in the Ground Electronic State}

Following electron attachment and decay to the ground electronic state, the charge-reduced ion was found to undergo spontaneous isomerization by ammonium proton migration onto the Ala amide carbonyl, forming an aminoketyl cation-radical (1). This reaction course was followed by B3LYP, CAM-B3LYP, and M06-2X calculations starting from the respective precursor dication geometries and does not appear to be an artifact of the DFT method used. In particular, the effects of self-electron interaction in B3LYP, that are attenuated in CAM-B3LYP and presumably corrected in M06-2X functionals, had no visible effect on the electronic properties of our peptide cation-radical. The vertical recombination energy $(\mathrm{RE})$ of $(\mathrm{AR}+2 \mathrm{H})^{2+}$ was $4.9-$ $5.0 \mathrm{eV}$ (from the respective B3-PMP2 and M06-2X single-point calculations); the adiabatic $\mathrm{RE}$ was $6.2 \mathrm{eV}$ which included the exothermic isomerization, $(\mathrm{AR}+2 \mathrm{H})^{2+} \rightarrow(\mathrm{AR}+2 \mathrm{H})^{+\bullet} \rightarrow \mathbf{1}$. Considering the Cs ionization energy $(3.89 \mathrm{eV})$, the aminoketyl cation-radical 1 receives $6.2-3.9=2.3 \mathrm{eV}$ excitation energy upon electron transfer from $\mathrm{Cs}$ when formed in the ground electronic state. Because of charge reduction, conformer 1 no longer experiences Coulomb repulsion between the Ala and Arg moieties and can undergo a very facile Arg side-chain rotation through TS1 (Scheme 2). This produces conformer 2 which is $28 \mathrm{~kJ} \mathrm{~mol}^{-1}$ more stable than $\mathbf{1}$ (Scheme 2, Table 1). Cation-radical 2 can then dissociate by $\mathrm{N}-\mathrm{C}_{\alpha}$ bond cleavage (TS2) to form the $z$ ion observed experimentally.

Aminoketyl cation-radical $\mathbf{1}$ is not the only ground state species possibly formed by electron attachment to (AR + $2 \mathrm{H})^{2+}$. Depending on the vibrational states of the precursor ion or charge-reduced intermediate state (see below), the electron can end up in the guanidine group to form cationradical 3 which is another local energy minimum. Table 1 data show that 3 is $54 \mathrm{~kJ} \mathrm{~mol}^{-1}$ less stable than $\mathbf{1}$. Formation of 3 necessitates bending the guanidinium group from nearplanar in $(\mathrm{AR}+2 \mathrm{H})^{2+}$ to puckered in 3. The ground-state PES of cation-radical 3 was investigated to locate the transition states for the loss of guanidine $\left[\mathbf{T S}\left(\mathrm{C}_{\delta}-\mathrm{N}_{\varepsilon}\right)\right]$ and the guanidinium hydrogen atoms $\left(\mathbf{T S}\left(\mathrm{N}_{\varepsilon}-\mathrm{H}_{\varepsilon}\right)\right.$, Scheme 3 , 


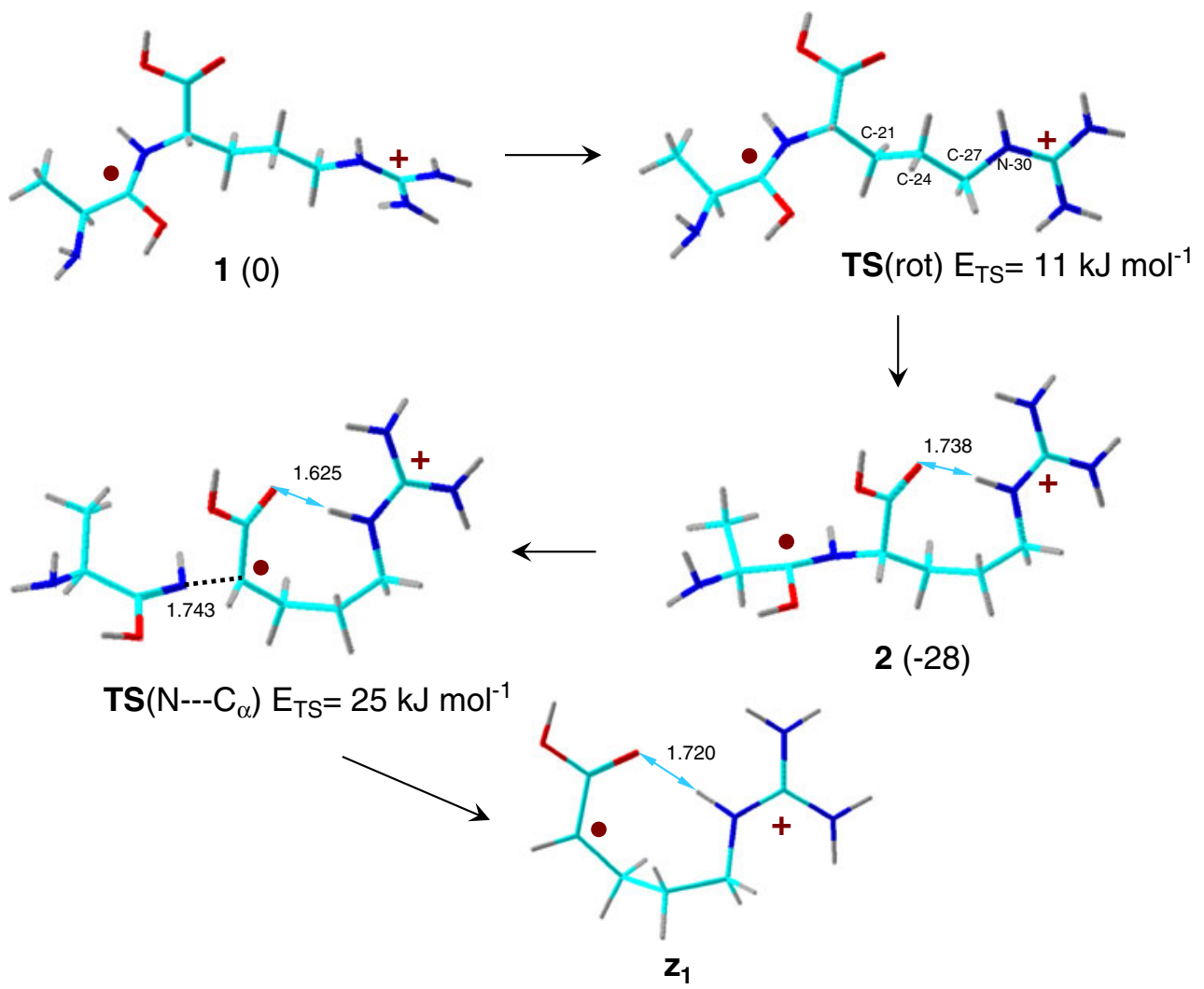

Scheme 2. Reaction scheme for isomerizations and dissociations of $(A R+2 H)^{+\bullet}$. The $T S(r o t)$ and $T S\left(N-C_{\alpha}\right)$ energies are from effective $\operatorname{CCSD}(T) / 6-311++G(3 d f, 2 p)$ single point energies relative to the respective reactants 1 and 2 and include the zeropoint energies. The atoms are color-coded as follows: green $=\mathrm{C}$, red $=\mathrm{O}$, blue $=\mathrm{N}$, gray $=\mathrm{H}$

Table 1). The loss of guanidine is energetically favored on the ground state PES at all levels of theory. Furthermore, RRKM calculations of the unimolecular rate constants favored the loss of guanidine over the loss of $\mathrm{H}$ by a factor of $>10^{2}$ (Figure S1, Supplementary Data). However, loss of guanidine is very minor in the electron transfer-induced dissociation spectrum, whereas the loss of $\mathrm{H}$ is a major dissociation channel [41].

The calculations indicated that the properties of the ground electronic states of charge-reduced $(\mathrm{AR}+2 \mathrm{H})^{+\bullet}$, as repre-

Table 1. Relative energies of $(\mathrm{AR}+2 \mathrm{H})^{+\bullet}$ Cation-Radicals

\begin{tabular}{|c|c|c|c|c|c|c|}
\hline \multirow[b]{3}{*}{ Species/reaction } & \multicolumn{6}{|c|}{ Relative energy ${ }^{a, b}$} \\
\hline & \multirow{2}{*}{$\frac{\text { B3LYP }}{6-31+G(d, p)}$} & B3-PMP2 ${ }^{\mathrm{C}}$ & CAM-B3LYP ${ }^{\mathrm{d}}$ & M06-2X & MP2 & $\operatorname{CCSD}(\mathrm{T})^{\mathrm{e}}$ \\
\hline & & \multicolumn{3}{|c|}{$6-311++\mathrm{G}(2 \mathrm{~d}, \mathrm{p})$} & \multicolumn{2}{|c|}{$6-311++G(3 d f, 2 p)$} \\
\hline $1 \rightarrow 2$ & -30 & -28 & -26 & -29 & -27 & -28 \\
\hline $1 \rightarrow 3$ & 54 & 49 & 57 & 63 & 51 & 54 \\
\hline $\mathrm{TS}(1 \rightarrow 2)$ & 10 & 10 & - & 11 & 10 & 11 \\
\hline $\mathbf{2} \rightarrow \mathrm{TS}\left(\mathrm{N}-\mathrm{C}_{\alpha}\right)$ & 5 & 5 & 20 & 18 & 8 & 25 \\
\hline $\mathbf{3} \rightarrow \mathbf{T S}\left(\mathrm{N}_{\varepsilon}-\mathrm{H}_{\varepsilon}\right)$ & 83 & 75 & 87 & 85 & 70 & 86 \\
\hline $\mathbf{3} \rightarrow(\mathrm{AR}+\mathrm{H})^{+}(\mathbf{4})+\mathrm{H}_{\varepsilon}{ }^{\bullet}$ & 83 & 61 & 79 & 71 & 49 & 67 \\
\hline $\mathbf{3} \rightarrow(\mathrm{AR}+\mathrm{H})^{+}(\mathbf{5})+\mathrm{H}_{\xi}^{\bullet}$ & 102 & 78 & 98 & 86 & - & - \\
\hline $3 \rightarrow(\mathrm{AR}+\mathrm{H})^{+}(\mathbf{6})+\mathrm{H}_{\phi} \cdot$ & 105 & 82 & 103 & 91 & - & - \\
\hline $\mathbf{3} \rightarrow(\mathrm{AR}+\mathrm{H})^{+}(7)+\mathrm{H}_{0}^{\bullet}$ & 105 & 81 & 103 & 88 & - & - \\
\hline $\mathbf{3} \rightarrow \mathbf{T S}\left(\mathrm{C}_{\delta}-\mathrm{N}_{\varepsilon}\right)$ & 51 & 57 & 73 & 72 & 68 & 73 \\
\hline $\mathbf{3} \rightarrow \mathbf{8}+$ guanidine & -6 & -4 & 3 & 14 & 9 & 13 \\
\hline
\end{tabular}

${ }^{\mathrm{a}}$ In units of $\mathrm{kJ} \mathrm{mol}^{-1}$.

${ }^{\mathrm{b}}$ Including zero-point vibrational energy corrections.

${ }^{\mathrm{c}}$ From averaged B3LYP and spin-projected MP2 single point energies.

${ }^{\mathrm{d}}$ From single-point energy calculations on fully optimized geometries.

${ }^{\mathrm{e}}$ From single-point energies on B3LYP/6-31+G(d,p) optimized geometries and by extrapolation: $E[\mathrm{CCSD}(\mathrm{T}) / 6-311++\mathrm{G}(3 \mathrm{df}, 2 \mathrm{p})] \approx E[\mathrm{CCSD}(\mathrm{T}) / 6-31+\mathrm{G}(\mathrm{d}, \mathrm{p})]$

$+E[\mathrm{PMP} 2 / 6-311++\mathrm{G}(3 \mathrm{df}, 2 \mathrm{p})]-E[\mathrm{PMP} 2 / 6-31+\mathrm{G}(\mathrm{d}, \mathrm{p})]$. 


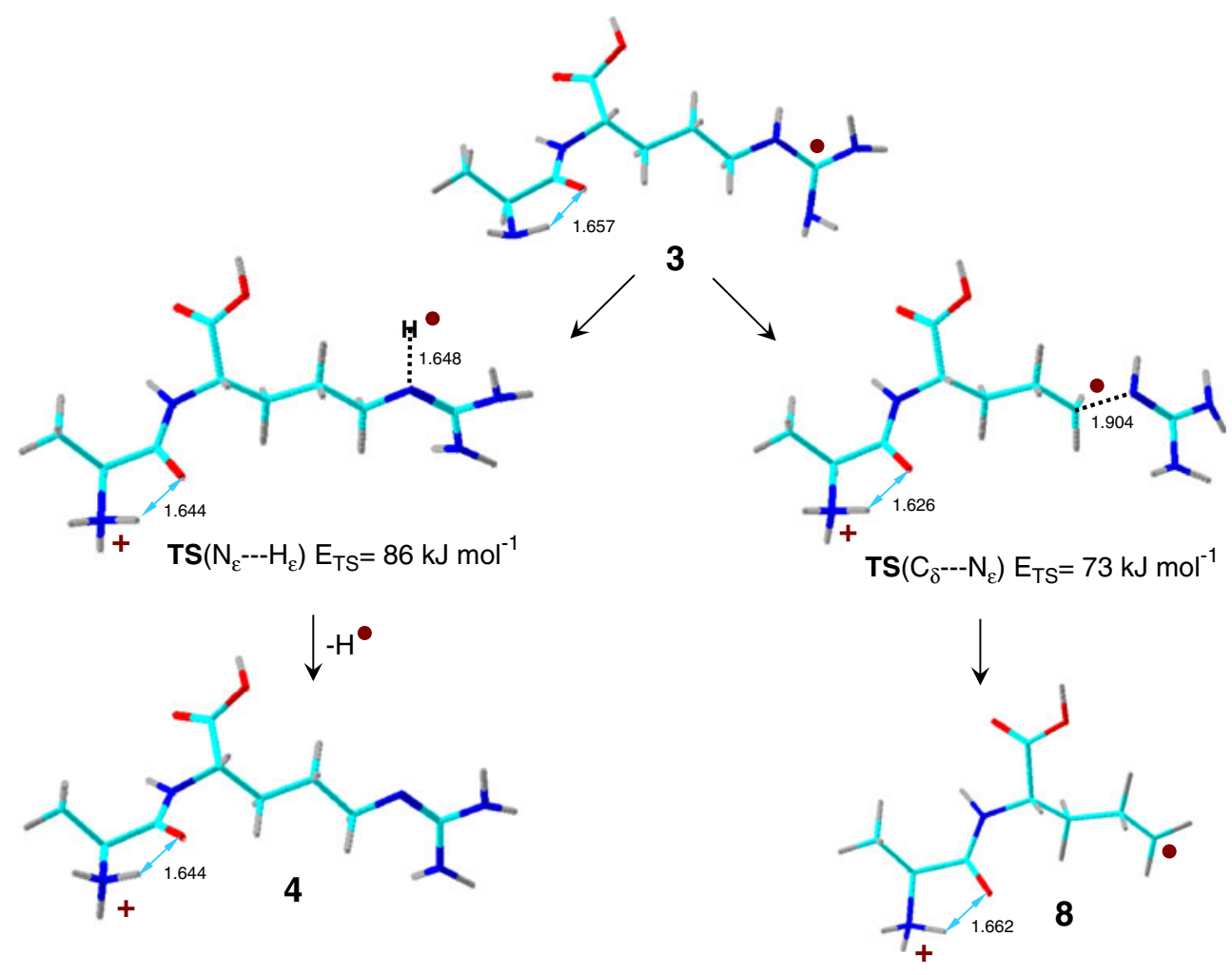

Scheme 3. Reaction scheme for dissociations of cation-radical 3. The $T S\left(N_{\varepsilon}-H_{\varepsilon}\right)$ and $T S\left(C_{\delta}-N_{\varepsilon}\right)$ energies are from effective $\operatorname{CCSD}(T) / 6-311++G(3 d f, 2 p)$ single point energies relative to 3 and include the zero-point energies. The atoms are color-coded as follows: green $=\mathrm{C}$, red $=\mathrm{O}$, blue $=\mathrm{N}$, gray $=\mathrm{H}$

sented by Structures $\mathbf{1}$ and $\mathbf{3}$, cannot fully explain the peptide cation-radical dissociations. The spontaneous isomerization to 1 hampers loss of ammonia from the N-terminus, which is a major dissociation $[41,59]$. The guanidinium radical $\mathbf{3}$ is predicted to eliminate guanidine, not an $\mathrm{H}$ atom, again contradicting the experimental data.

\section{Ehrenfest Dynamics of the Ground and Excited Electronic States of $(A R+2 H)^{+}$}

Ehrenfest dynamics of the excited states was first run with the initial nuclear kinetic energy set to zero. In each case, the principal reaction revealed by B3LYP calculations was proton transfer from the $\mathrm{N}$-terminal ammonium to the amide carbonyl oxygen forming an aminoketyl radical (1). Figure 4 shows that the ammonium $\mathrm{N}-\mathrm{H}$ bond of the migrating proton was elongated to $1.8 \AA$ within $60 \mathrm{fs}$, which corresponds to ca. five vibrational periods for this bond in the ion. Upon migration, the $\mathrm{H}$ atom first overshoots its equilibrium distance from the amine $\mathrm{N}$ atom due to hydrogen bonding in $\mathbf{1}$ and continues to oscillate, while establishing a resonance with the $\mathrm{N}-\mathrm{C}_{\alpha}$ bond stretch. The hydrogen atom will eventually attain its equilibrium position while its kinetic energy is dissipated into the other internal degrees of freedom of $\mathbf{1}$. This was further corroborated by examining the rotation of the remote Arg side chain which requires only $11 \mathrm{~kJ} \mathrm{~mol}^{-1}$ in the transition state to form a more stable H-bonded conformer $2, \Delta H_{0}(\mathbf{1} \rightarrow \mathbf{2})=-28 \mathrm{~kJ}$ $\mathrm{mol}^{-1}$ (Table 1, Scheme 2). The N-30-C-27-C-24-C-21 dihedral angle $(\theta)$ for the side-chain rotation oscillates between $165-180^{\circ}$ within $330 \mathrm{fs}$ but does not reach the transition state geometry of $\theta=129^{\circ}$ (Scheme 2). It is worth noting that even with full internal energy relaxation in 1, the RRKM calculated rate constant for the rotation, $k=2.5 \times 10^{10} \mathrm{~s}^{-1}$, indicates that the isomerization would not occur on the 330 fs time scale.

The final result of the dynamics calculations is equivalent to that produced by a gradient optimization of the vertically reduced radical cation using the standard algorithm and regardless of the type of the DFT method (B3LYP, CAMB3LYP, or M06-2X), as discussed above. This confirms that the Ehrenfest dynamics can reproduce the results from conventional computational methods by correctly evaluating the intramolecular electron transfer from the initial excited state to the ground state PES. The potential energy drop due to the electron transfer from Cs $(5.03-3.89 \mathrm{eV}=1.14 \mathrm{eV}=$ $110 \mathrm{~kJ} \mathrm{~mol}^{-1}$ ), combined with proton migration and side chain rotation $\left(110+104+28=242 \mathrm{~kJ} \mathrm{~mol}^{-1}\right)$, is eventually converted to the vibrational energy of the aminoketyl intermediate 2 to drive $\mathrm{N}-\mathrm{C}_{\alpha}$ bond cleavage which requires an activation energy of $25 \mathrm{~kJ} \mathrm{~mol}^{-1}(\operatorname{CCSD}(\mathrm{T})$ data, Table 1) and leads to the $z_{1}$ ion seen in the mass spectrum [41]. RRKM calculations on the $\operatorname{CCSD}(\mathrm{T})$ ground state potential energy surface indicate unimolecular rate constants for the 


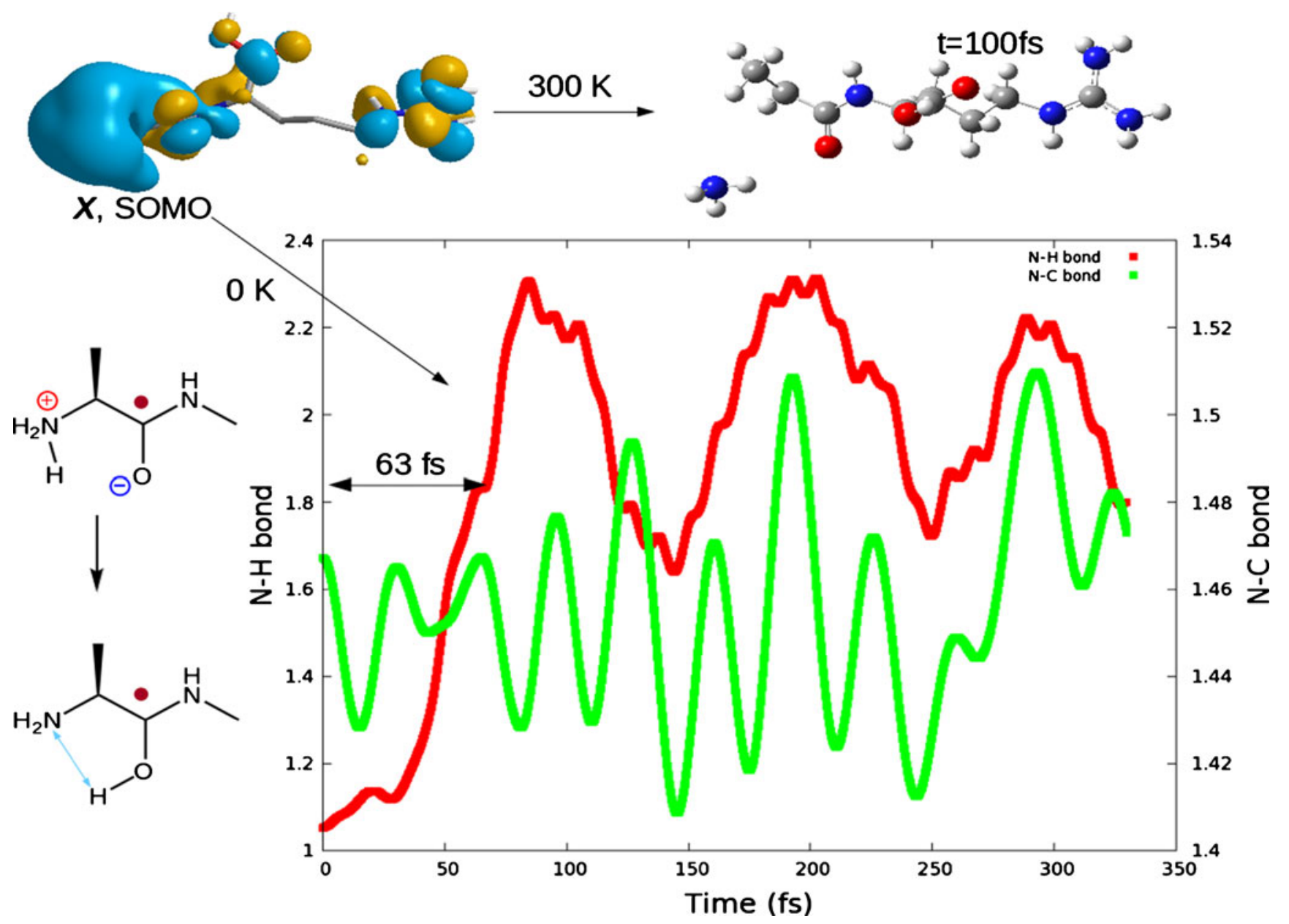

Figure 4. Ehrenfest dynamics trajectories for $\mathrm{H}$ atom migration and loss of ammonia starting from the SOMO $(\boldsymbol{X})$ state

$\mathrm{N}-\mathrm{C}_{\alpha}$ bond cleavage in 2 to be $10^{10} \leq k \leq 10^{11} \mathrm{~s}^{-1}$ corresponding to ion lifetimes of $10-100$ ps over a broad range of internal energies (Figure S2, Supplementary Data). Referring to the experimental data [41], resonant electron transfer from a Cs atom $(\mathrm{IE}=3.894 \mathrm{eV})$ to the $(\mathrm{AR}+2 \mathrm{H})^{2+}$ ion having vertical recombination energies of $5.03-5.07 \mathrm{eV}$ (ref. [41]) is estimated to occur at a collisional cross section of $5 \times 10^{-14} \mathrm{~cm}^{2}$ [43]. This would deposit $242 \mathrm{~kJ} \mathrm{~mol}^{-1}$ in 2 and promote $\mathrm{N}-\mathrm{C}_{\alpha}$ bond cleavage with $k=4.7 \times 10^{10} \mathrm{~s}^{-1}$ (Figure S2). Thus the expected ion lifetime $(t=1 / k=2.1 \times$ $10^{-11} \mathrm{~s}$ ) is substantially longer than what can be currently modeled with Eherenfest dynamics $\left(3.3 \times 10^{-13} \mathrm{~s}\right)$, but substantially shorter than the experimental time scale $(5 \mu \mathrm{s})[41]$.

In the second set of trajectories, thermal internal velocities were included in the $(\mathrm{AR}+2 \mathrm{H})^{2+}$ ion. This resulted in different reaction pathways after the initial electron attachment in different molecular orbitals. Attachment of the electron in the SOMO resulted in a dissociation of the N-terminal ammonium group within 330 fs. This pathway represents the major dissociation promoted by electron attachment and is consistent with previous ${ }^{15} \mathrm{~N}$ labeling studies that identified the ammonia molecule as originating mainly from the N-terminal amino group [59]. Hence, inclusion of thermal energy resulted in a dynamic instability of the vertically reduced $\mathbf{1}$ which dissociated spontaneously during a few molecular vibrations.

Ehrenfest dynamics calculations on the SOMO electronic state using the CAM-B3LYP functional yielded similar results. Figure S3 (Supplemental Data) shows that electron attachment to $(\mathrm{AR}+2 \mathrm{H})^{2+}$ causes local excitation of the $\mathrm{H}_{3} \mathrm{~N}-\mathrm{C}_{\alpha}$ bond which undergoes one vibration with a $60 \mathrm{fs}$ period before complete dissociation and $\mathrm{NH}_{3}$ molecule departure. This indicates that long-range self-electron interactions in B3LYP did not affect the results, presumably because the electron reorganization was mainly localized within the $\mathrm{H}_{3} \mathrm{NCH}\left(\mathrm{CH}_{3}\right) \mathrm{CONH}$ group. There was a slight difference in the B3LYP and CAM-B3LYP dissociation dynamics in that the former proceeded to a faster $\mathrm{H}_{3} \mathrm{~N}-\mathrm{C}_{\alpha}$ bond dissociation, as shown by comparing the timedependent data in Figure 2 and Figure S3. These differences presumably reflect the different B3LYP and CAM-B3LYP force constants for the $\mathrm{H}_{3} \mathrm{~N}-\mathrm{C}_{\alpha}$ stretching mode and the $\mathrm{H}_{3} \mathrm{~N}-\mathrm{C}_{\alpha}-\mathrm{C}=\mathrm{O}$ torsional mode. Loss ammonia in the ground electronic state is facilitated by rotation about the $\mathrm{H}_{3} \mathrm{~N}_{-} \mathrm{C}_{\alpha^{-}}$ $\mathrm{C}=\mathrm{O}$ bond to reach the low-lying transition state [60]. 
Previous ground state calculations indicated that the elimination of ammonia was substantially exothermic, required a very low transition state, and produced an ionmolecule complex that was $>200 \mathrm{~kJ} \mathrm{~mol}^{-1}$ below the reactant [29]. Because of the enormous exothermicity of the dissociation, the evolution along the reaction coordinate in the first 100 fs clearly involves or leads to a point of no return, where the system continues to move on the steeply descending potential energy surface to eventually dissociate. It would be very interesting to investigate the entire development on a longer time scale of ca. $10-100$ ps to establish the dynamics of the ammonia departure or complexation by hydrogen bonding with the fragment ion, as well as the exothermic and presumably concurrent folding of the peptide fragment, analogous to that shown for ion $\mathbf{1}$ in Scheme 2. Unfortunately, the Ehrenfest dynamics calculations reported here are at the limit of the current technology, and longer trajectories cannot be studied.

\section{LUMO Initial State}

Electron attachment in the LUMO localizes the electron in the arginine guanidinium group. Dynamics calculations at initial thermal kinetic energies indicate that electron attachment to the LUMO initiates an umbrella vibration of the guanidinium central carbon, out-of-plane relative to the surrounding nitrogen atoms. Over the course of $330 \mathrm{fs}$, this oscillation goes through two full 103 and 130 fs periods (Figure 5). Converting these periods to energy values by $E\left(\mathrm{Jmol}^{-1}\right)=\frac{h N_{A}}{\tau}$ yields $E=605 \mathrm{Jmol}^{-1}$ and $488 \mathrm{Jmol}^{-1}$, respectively. There exists a local minimum (3) where the $\mathrm{N}_{\varepsilon^{-}}$ $\mathrm{N}_{\eta 1}-\mathrm{N}_{\eta 2}-\mathrm{C}_{\delta}$ dihedral is puckered to $27.8^{\circ}$ and calculated to be $-640 \mathrm{Jmol}^{-1}$ relative to the vertically attached cationradical structure. Thus, the period of the out-of-plane vibration closely corresponds to that predicted for the energy gap between the vertically reduced structure and the puckered local minimum. From the puckered local minimum, the activation energy for cleavage of the $\mathrm{N}_{\varepsilon}-\mathrm{C}_{\delta}$ bond $\left(\operatorname{TS}\left(C_{\delta}-\mathrm{N}_{\varepsilon}\right)\right)$ has been calculated to be $73 \mathrm{~kJ} \mathrm{~mol}^{-1}$. This is much greater than the available kinetic energy in the LUMO state according to our simulations, which explains why we do not see loss of the neutral guanidine fragment from the arginine residue. However, our dynamics calculations do show that the radical site can be sequestered on the arginine side-chain in the LUMO state, which inhibits competing reaction pathways that have lower activation barriers from occurring on the short time scale.

Ehrenfest dynamics calculations starting from the LUMO state and using CAM-B3LYP gave results, which were completely analogous to those from B3LYP. This indicates
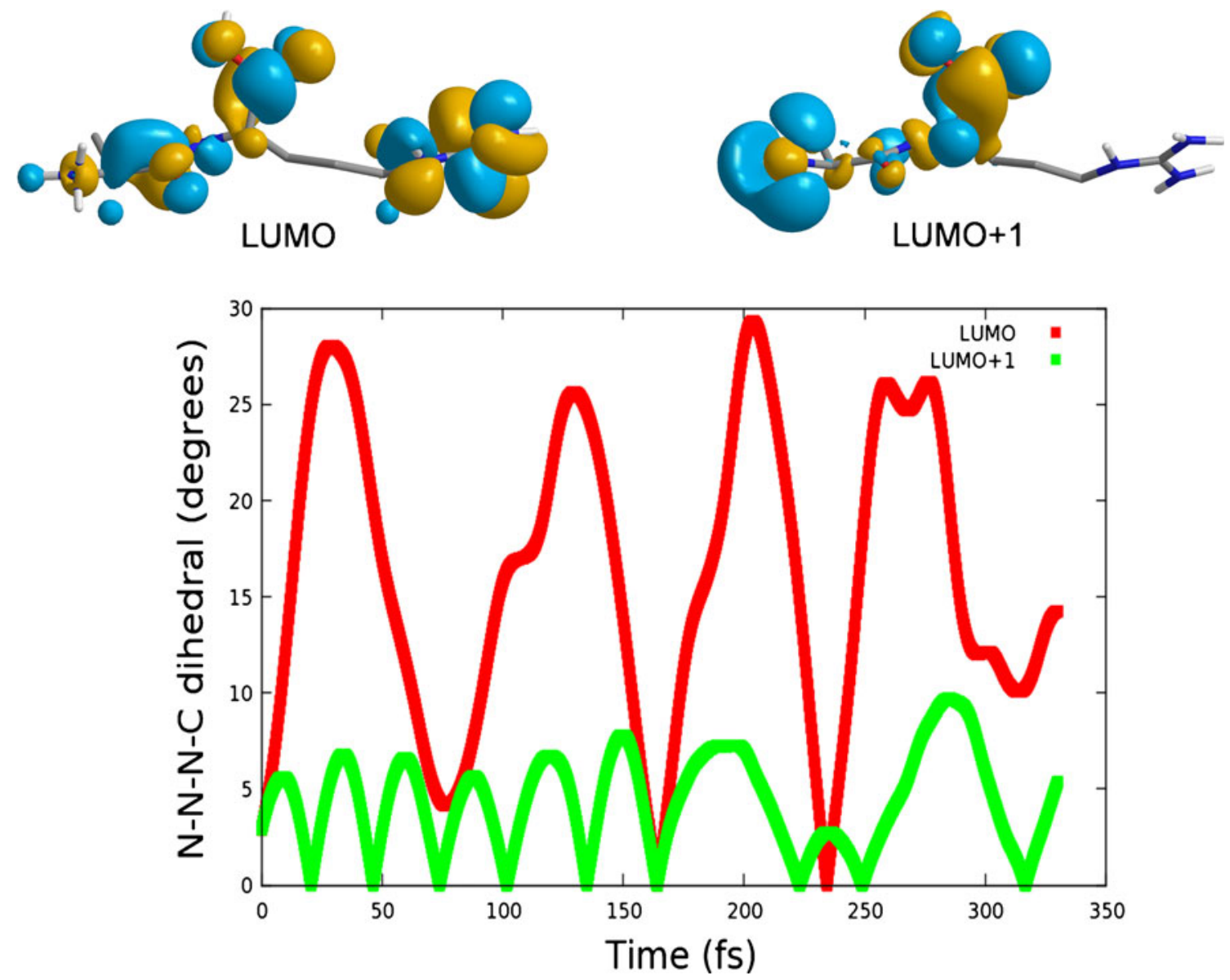

Figure 5. Dynamics trajectory for guanidinium umbrella vibrations starting from the LUMO (A) and LUMO+1 (B) states 
that long-range self-electron interactions in B3LYP did not affect the results, presumably because the electron reorganization was mainly localized within the guanidinium group. Snapshots of the LUMO state trajectory at $0,20,45$, and 100 fs (Figure S4, Supplementary Material) and the changes in the guanidinium group dihedral angle $(\theta)$ show its puckering as a result of electron attachment and formation of a guanidinium radical.

\section{LUMO+1 Initial State}

Dynamics calculations beginning from the LUMO +1 state did not show any significant chemical reactivity on the 330 fs time scale (Figure 5). Monitoring Mulliken spin densities on diagnostic atoms showed a rapid oscillation ( $<4 \mathrm{fs}$ period) of spin density between the backbone atoms and a gradual migration of spin density to the arginine sidechain. The rapid oscillation arises from the coherence of multiple excited states, which has been seen in other work $[61,62]$. Ehrenfest dynamics calculations starting from the LUMO+1 state and using CAM-B3LYP/4-31G(d) gave results that were analogous but not identical to those describing the LUMO state. Figure S5 (Supplementary Material) shows the puckering and stretching vibrations of the guanidine groups that change the dihedral angle $(\theta)$ as well as the $\mathrm{H}_{2} \mathrm{~N}-\mathrm{C}$ bond lengths in the LUMO+1 state. The stretching vibrations were much less pronounced in the
LUMO state, indicating that it and the LUMO+1 state did not coalesce to a common state during the 100 fs long trajectory.

\section{LUMO+2 Initial State}

Attachment of the electron to the LUMO +2 orbital resulted in rapid ejection of $\mathrm{H}_{\varepsilon}$ from the arginine guanidinium group (Figure 6). Dissociation of the $\mathrm{H}_{\varepsilon}-\mathrm{N}_{\varepsilon}$ bond requires $86+54=$ $140 \mathrm{~kJ} \mathrm{~mol}^{-1}$ on the ground PES relative to 1 (Table 1), which makes it noncompetitive with the other dissociations. However, when starting from the LUMO +2 state, the guanidinium hydrogen atom is almost immediately ejected. Ehrenfest dynamics calculations starting from the LUMO + 2 state and using CAM-B3LYP showed initial excitation of the $\mathrm{H}_{\varepsilon}-\mathrm{N}_{\varepsilon}$ bond, which was analogous to the result from B3LYP. This indicated that long-range self-electron interactions in B3LYP did not affect the results, presumably because the electron reorganization was mainly localized within the guanidinium group. Figure S6, (Supplementary Material) shows the progress of the $\mathrm{H}_{\varepsilon}-\mathrm{N}_{\varepsilon}$ bond dissociation after $10 \mathrm{fs}$ as obtained by CAM-B3LYP Ehrenfest dynamics. There was slight difference between the B3LYP and CAMB3LYP trajectory in that, according to the latter, the $\mathrm{H}_{\varepsilon}-\mathrm{N}_{\varepsilon}$ bond underwent a vibration before rupture. Note that the LUMO +2 state is ca. $104+50=154 \mathrm{~kJ} \mathrm{~mol}^{-1}$ above 1 , and $154-140=14 \mathrm{~kJ} \mathrm{~mol}^{-1}$ above $\mathbf{T S}\left(\mathrm{H}_{\varepsilon}-\mathrm{N}_{\varepsilon}\right)$, so that the
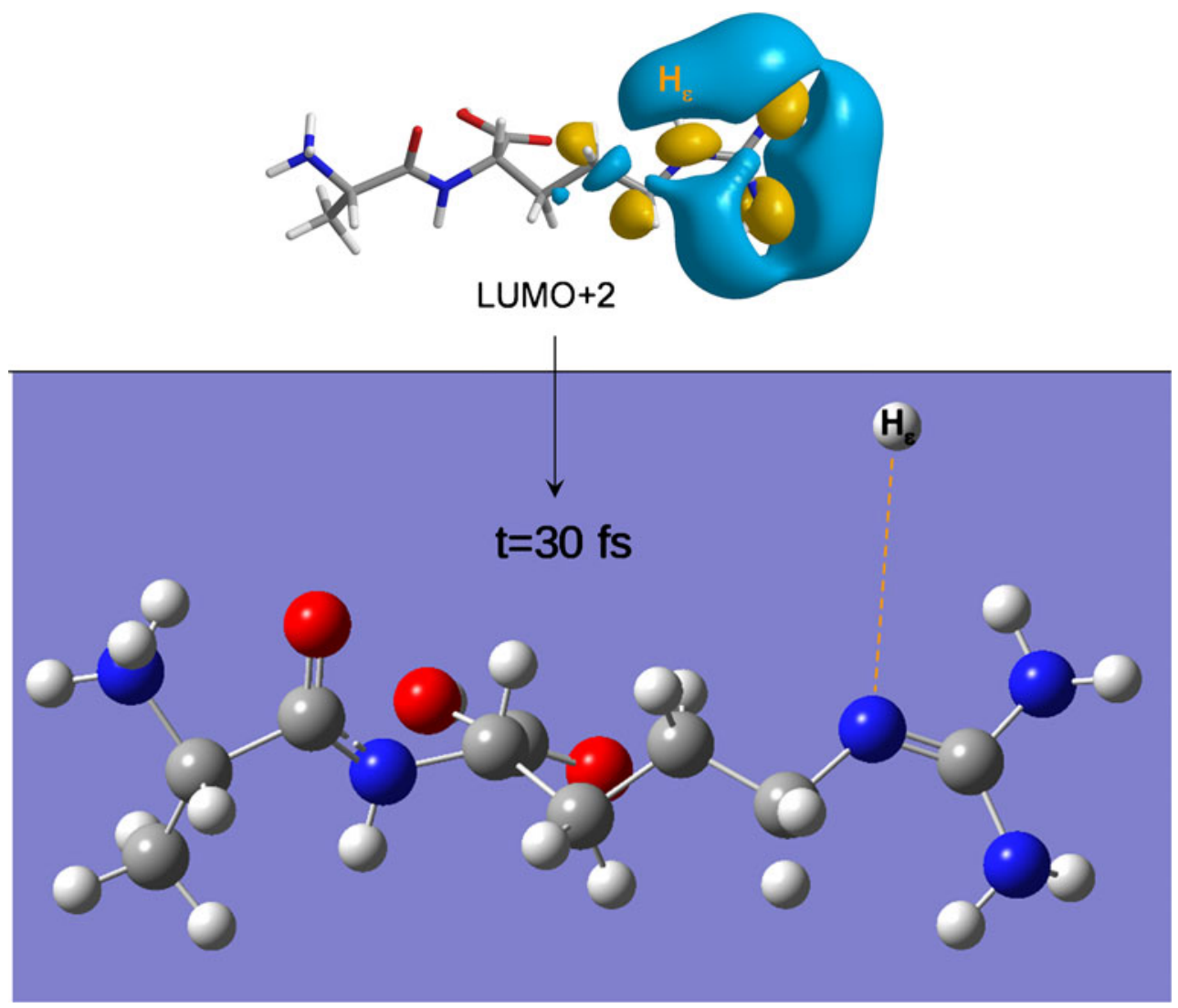

Figure 6. Dynamics trajectory for $\mathrm{H}_{\varepsilon}-\mathrm{N}_{\varepsilon}$ bond cleavage starting from the LUMO+2 (C) state 
dissociation originating from the LUMO +2 state is thermodynamically favorable. The B3LYP Ehrenfest dynamics calculations indicate that after 15 fs $\mathrm{H}_{\varepsilon}$ has passed $1.5 \AA$ distance from $\mathrm{N}_{\varepsilon}$, traveling at the velocity of $1.69 \times 10^{13} \mathrm{bohr} / \mathrm{s}$ corresponding to a kinetic energy release of $E_{\mathrm{kin}}=0.0043 \mathrm{eV}$. The repulsive potential energy surface of the LUMO +2 state along the $\mathrm{H}_{\varepsilon}-\mathrm{N}_{\varepsilon}$ coordinate is explained by the nature of the LUMO +2 state wave function, which is represented by an antibonding $\sigma^{*}$ orbital intersecting the guanidinium $\mathrm{N}-\mathrm{H}$ bonds. Thus, the calculations indicate that the loss of $\mathrm{H}_{\varepsilon}$ is made possible in an excited state of $\mathbf{1}$ prior to vibrational relaxation. It is interesting to note that among the losses of various guanidinium hydrogen atoms, the loss of $\mathrm{H}_{\varepsilon}$ has the lowest threshold energy to give ion $4\left(86 \mathrm{~kJ} \mathrm{~mol}^{-1}\right.$ relative to 3, Table 1). Losses of the other guanidinium hydrogen atoms are more endothermic to give tautomeric ions 5-7 (Table 1).

In conclusion, Ehrenfest dynamics calculations allow us to interpret the ExD experimental data and illustrate how excited states contribute to electron-based dissociations. We have shown that at low internal energies, the Ehrenfest dynamics can produce results that are analogous to those from conventional Born-Oppenhemier models, namely predicting isomerization to an aminoketyl radical which is a local energy minimum. This result was obtained by calculations using three different density functionals, including those that account for long-range self-electron interactions. At higher internal energies, decay from the ground electronic state proceeds by dissociation along the reaction pathway with the lowest activation energy, which is also in agreement with conventional, stationary points seeking methods. However, the Ehrenfest dynamics showed that when an electron is attached to an excited electronic state, the system can follow state-selective reaction pathways that would not be favored on the ground state PES. The predicted pathway for loss of $\mathrm{H}$ from the LUMO +2 state qualitatively explains its occurrence in the experimental spectrum. The LUMO and LUMO + 1 states are no reactive on the short time scale of these calculations. The LUMO +1 state indicates formation of a guanidinium radical which is a local energy minimum. At sufficient internal vibrational energy this state is expected to dissociate by loss of guanidine, which is not observed experimentally. These results indicate that the dissociation pathways of peptide cation-radicals upon electron attachment are governed by the population of particular valence electronic states. Some states, such as the LUMO + 2 have distinct reactivity, others can nonadiabatically cross to the ground state or other low-energy states. The crossings are facilitated by the close energy spacing of these states, even in a small dipeptide cationradicals studied here and more so in larger peptides [34, 43]. This is of interest not only because of the unusual contribution from the excited state electronic structure, but because it provides a strong theoretical foundation for interpreting ExD mass spectra using the excited states accessed by vertical electron attachment. If the most abundant fragments in a spectrum can be determined from the character of excited states, this will provide a roadmap for predicting peptide backbone cleavages using TD-DFT. This would provide a useful tool for confirming amino acid sequence and peptide secondary structure using mass spectrometry.

A final note concerns the internal vibrational energy redistribution (IVR) in charge-reduced $(\mathrm{AR}+2 \mathrm{H})^{+\bullet}$. The dynamics calculations indicate that the LUMO +2 state is weakly bound or repulsive along the $\mathrm{N}_{\varepsilon}-\mathrm{H}_{\varepsilon}$ coordinate, and the loss of $\mathrm{H}_{\varepsilon}$ proceeds at a rate which is faster than IVR. The loss of ammonia from vibrationally excited $(\mathrm{AR}+2 \mathrm{H})^{+\bullet}$ occurs within $100 \mathrm{fs}$, which is also faster than IVR. In contrast, the $\mathrm{N}-\mathrm{C}_{\alpha}$ bond dissociation does not show a significant progress in 330 fs and, according to RRKM calculations, proceeds after substantial randomization of the vibrational energy in the aminoketyl radical 2.

\section{Acknowledgments}

The authors acknowledge support for this work by the National Science Foundation (grants CHE-01055132 to F.T., CHE-CAREER 0844999 to X.L., and CHE-0342956 for computations). The Department of Chemistry Computational Center has been supported jointly by the NSF and University of Washington.

\section{References}

1. Hakånsson, K., Klassen, J.S.: Electrospray and MALDI Mass Spectrometry, 2nd edn, pp. 571-630. Wiley, New York (2010)

2. Syka, J.E.P., Coon, J.J., Schroeder, M.J., Shabanowitz, J., Hunt, D.F.: Peptide and protein sequence analysis by electron transfer dissociation mass spectrometry. Proc. Natl. Acad. Sci. U. S. A. 101, 9528-9533 (2004)

3. Zubarev, R.A., Kelleher, N.L., McLafferty, F.W.: Electron capture dissociation of multiply charged protein cations. A nonergodic process. J. Am. Chem. Soc. 120, 3265-3266 (1998)

4. Zubarev, R.A.: Reactions of polypeptide ions with electrons in the gas phase. Mass Spectrom. Rev. 22, 57-77 (2003)

5. Savitski, M.M., Kjeldsen, F., Nielsen, M.L., Zubarev, R.A.: Complementary sequence preferences of electron-capture dissociation and vibrational excitation in fragmentation of polypeptide polycations. Angew. Chem. Int. Ed. Engl. 45, 5301-5306 (2006)

6. Van der Rest, G., Hui, R., Frison, G., Chamot-Rooke, J.: Dissociation channel dependence on peptide size observed in electron capture dissociation of tryptic peptides. J. Am. Soc. Mass Spectrom. 22, 16311644 (2011)

7. Fung, Y.M.E., Chan, T.W.D.: Experimental and theoretical investigations of the loss of amino acid side chains in electron capture dissociation of model peptides. J. Am. Soc. Mass Spectrom. 16, 15231535 (2005)

8. Cooper, H.J.: Investigation of the presence of $\mathrm{b}$ ions in electron capture dissociation mass spectra. J. Am. Soc. Mass Spectrom. 16, 1932-1940 (2005)

9. Lin, C., Cournoyer, J.J., O'Connor, P.B.: Use of a double resonance electron capture dissociation experiment to probe fragment intermediate lifetimes. J. Am. Soc. Mass Spectrom. 17, 1605-1615 (2006)

10. O'Connor, P.B., Lin, C., Cournoyer, J.J., Pittman, J.L., Belyayev, M., Budnik, B.A.: Long-lived electron capture dissociation product ions experience radical migration via hydrogen abstraction. J. Am. Soc. Mass Spectrom. 17, 576-585 (2006)

11. Jensen, C.S., Holm, A.I.S., Zettergren, H., Overgaard, J.B., Hvelplund, P., Nielsen, S.B.: On the charge partitioning between $\mathrm{c}$ and $\mathrm{z}$ fragments formed after electron- capture induced dissociation of charge-tagged 
lys-lys and ala-lys dipeptide cations. J. Am. Soc. Mass Spectrom. 20, 1881-1889 (2009)

12. Vorobyev, A., Ben Hamidane, H., Tsybin, Y.O.: Electron capture dissociation product ion abundances at the $\mathrm{X}$ amino acid in RAAAA-XAAAAK peptides correlate with amino acid polarity and radical stability. J. Am. Soc. Mass Spectrom. 20, 2273-2283 (2009)

13. Ben Hamidane, H., He, H., Tsybin, O.Y., Emmett, M.R., Hendrickson, C.L., Marshall, A.G., Tsybin, Y.O.: Periodic sequence distribution of product ion abundances in electron capture dissociation of amphipathic peptides and proteins. J. Am. Soc. Mass Spectrom. 20, 1182-1192 (2009)

14. Crizer, D.M., McLuckey, S.S.: Electron transfer dissociation of amide nitrogen methylated polypeptide cations. J. Am. Soc. Mass Spectrom. 20, 1349-1354 (2009)

15. Chan, W.Y.K., Chan, T.W.D.: Natural structural motifs that suppress peptide ion fragmentation after electron capture. J. Am. Soc. Mass Spectrom. 21, 1235-1244 (2010)

16. Jensen, C.S., Wyer, J.A., Nielsen, S.B.: Electron capture induced dissociation of dipeptide dications: Where does the charge go? Phys. Chem. Chem. Phys. 12, 12961-12963 (2010)

17. Haag, N., Holm, A.I.S., Johansson, H.A.B., Zettergren, H., Schmidt, H. T., Nielsen, S.B., Hvelplund, P., Cederquist, H.: Electron capture induced dissociation of doubly protonated pentapeptides: Dependence on molecular structure and charge separation. J. Chem. Phys. 134, 035102/1-035102/6 (2011)

18. Moore, B.N., Ly, T., Julian, R.R.: Radical conversion and migration in electron capture dissociation. J. Am. Chem. Soc. 133, 6997-7006 (2011)

19. Zubarev, R.A., Kruger, N.A., Fridriksson, E.K., Lewis, M.A., Horn, D. M., Carpenter, B.K., McLafferty, F.W.: Electron capture dissociation of gaseous multiply-charged proteins is favored at disulfide bonds and other sites of high hydrogen atom affinity. J. Am. Chem. Soc. 121, 2857-2862 (1999)

20. Tureček, $\mathrm{F} . \mathrm{N}-\mathrm{C}_{\alpha}$ bond dissociation energies and kinetics in amide and peptide radicals. Is the dissociation a nonergodic process? $\mathrm{J}$. Am. Chem. Soc. 125, 5954-5963 (2003)

21. Chung, T.W., Tureček, F.: Proper and improper aminoketyl radicals in electron-based peptide dissociations. Int. J. Mass Spectrom. 301, 55-61 (2011)

22. Turecek, F., Jones, J.W., Towle, T., Panja, S., Nielsen, S.B., Hvelplund, P., Paizs, B.: Hidden histidine rearrangements upon electron transfer to gas-phase peptide ions. Experimental evidence and theoretical analysis. J. Am. Chem. Soc. 130, 14584-14596 (2008)

23. Patriksson, A., Adams, C., Kjeldsen, F., Raber, J., van der Spoel, D., Zubarev, R.A.: Prediction of $\mathrm{NC} \alpha$ bond cleavage frequencies in electron capture dissociation of Trp-cage dications by force-field molecular dynamics simulations. Int. J. Mass Spectrom. 248, 124-130 (2006)

24. Robinson, E.W., Leib, R.D., Williams, E.R.: The role of conformation on electron capture dissociation of ubiquitin. J. Am. Soc. Mass Spectrom. 17, 1469-1479 (2006)

25. Skurski, P., Sobczyk, M., Jakowski, J., Simons, J.: Possible mechanisms for protecting $\mathrm{NC} \alpha$ bonds in helical peptides from electroncapture (or transfer) dissociation. Int. J. Mass Spectrom. 265, 197-212 (2007)

26. Tureček, F., Syrstad, E.A., Seymour, J.L., Chen, X., Yao, C.: Peptide cation-radicals. A computational study of the competition between peptide $\mathrm{N}-\mathrm{C}_{\alpha}$ bond cleavage and loss of the side chain in the [GlyPhe$\left.\mathrm{NH}_{2}+2 \mathrm{H}\right]^{+\bullet}$ cation radical. J. Mass Spectrom. 38, 1093-1104 (2003)

27. Sobczyk, M., Anusiewicz, I., Berdys-Kochanska, J., Sawicka, A. Skurski, P., Simons, J.: Coulomb-assisted dissociative electron attachment: Application to a model peptide. J. Phys. Chem. A 109, 250-258 (2005)

28. Syrstad, E.A., Tureček, F.: Toward a general mechanism of electroncapture dissociation. J. Am. Soc. Mass Spectrom. 16, 208-224 (2005)

29. Tureček, F., Chen, X., Hao, C.: Where does the electron go? Electron distribution and reactivity of peptide cation-radicals formed by electron transfer in the gas phase. J. Am. Chem. Soc. 130, 8818-8833 (2008)

30. Anusiewicz, I., Berdys-Kochanska, J., Simons, J.: Electron attachment step in electron capture dissociation (ECD) and electron transfer dissociation (ETD). J. Phys. Chem. A 109, 5801-5813 (2005)

31. Simons, J.: Mechanisms for $\mathrm{S}-\mathrm{S}$ and $\mathrm{N}-\mathrm{C}_{\alpha}$ bond cleavage in peptide ECD and ETD mass spectrometry. Chem. Phys. Lett. 484, 81-95 (2010)

32. Simons, J.: Analytical model for rates of electron attachment and intramolecular electron transfer in electron transfer dissociation mass spectrometry. J. Am. Chem. Soc. 132, 7074-7085 (2010)
33. Sobczyk, M., Anusiewicz, I., Berdys-Kochanska, J., Sawicka, A., Skurski, P., Simons, J.: Coulomb-assisted dissociative electron attachment: Application to a model peptide. J. Phys. Chem. A 109, 250-259 (2003)

34. Tureček, F., Chung, T.W., Moss, C.L., Wyer, J.A., Ehlerding, A., Holm, A.I.S., Zettergren, H., Nielsen, S.B., Hvelplund, P., ChamotRooke, J., Bythell, B., Paizs, B.: The histidine effect. Electron transfer and capture cause different dissociations and rearrangements of histidine peptide cation-radicals. J. Am. Chem. Soc. 132, 1072810740 (2010)

35. Chamot-Rooke, J., Malosse, C., Frison, G., Tureček, F.: Electron capture in charge- tagged peptides. Evidence for the role of excited electronic states. J. Am. Soc. Mass Spectrom. 18, 2146-2161 (2007)

36. Furche, F., Ahlrichs, A.: Adiabatic time-dependent density functional methods for excited state properties. J. Chem. Phys. 117, 7433-7447 (2002)

37. Li, X., Tully, J.C., Schlegel, H.B., Frisch, M.J.: Ab initio Ehrenfest dynamics. J. Chem. Phys. 123, 084106/1-084106/7 (2005)

38. Isborn, C.M., Li, X., Tully, J.C.: Time-dependent density functional theory Ehrenfest dynamics: Collisions between atomic oxygen and graphite clusters. J. Chem. Phys. 126, 134307/1-134307/7 (2007)

39. Liang, W., Chapman, C.T., Li, X.: Efficient first-principles electronic dynamics. J. Chem. Phys. 134, 184102/1-184102/7 (2011)

40. Bakken, V., Helgaker, T., Uggerud, E.: Models of fragmentations induced by electron attachment to protonated peptides. Eur. J. Mass Spectrom. 10, 625-638 (2004)

41. Panja, S., Nielsen, S.B., Hvelplund, P., Tureček, F.: Inverse hydrogen atom migration in arginine-containing peptide ions upon electron transfer. J. Am. Soc. Mass Spectrom. 19, 1726-1742 (2008)

42. Frisch, M.J., Trucks, G.W., Schlegel, H.B., Scuseria, G.E., Robb, M.A., Cheeseman, J.R., Scalmani, G., Barone, V., Mennucci, B., Petersson, G. A., Nakatsuji, H., Caricato, M., Li, X., Hratchian, H.P., Izmaylov, A.F., Bloino, J., Zheng, G., Sonnenberg, J.L., Hada, M., Ehara, M., Toyota, K., Fukuda, R., Hasegawa, J., Ishida, M., Nakajima, T., Honda, Y., Kitao, O., Nakai, H., Vreven, T., Montgomery Jr., J.A., Peralta, J.E., Ogliaro, F., Bearpark, M., Heyd, J.J., Brothers, E., Kudin, K.N., Staroverov, V.N., Kobayashi, R., Normand, J., Raghavachari, K., Rendell, A., Burant, J.C., Iyengar, S.S., Tomasi, J., Cossi, M., Rega, N., Millam, J.M., Klene, M., Knox, J.E., Cross, J.B., Bakken, V., Adamo, C., Jaramillo, J., Gomperts, R., Stratmann, R.E., Yazyev, O., Austin, A.J., Cammi, R., Pomelli, C., Ochterski, J.W., Martin, R.L., Morokuma, K., Zakrzewski, V.G., Voth, G.A., Salvador, P., Dannenberg, J.J., Dapprich, S., Daniels, A.D., Farkas, O., Foresman, J.B., Ortiz, J.V., Cioslowski, J., Fox, D.J.: Gaussian 09, Revision A.02. Gaussian, Inc, Wallingford (2009)

43. Moss, C.L., Chung, T.W., Wyer, J.A., Nielsen, S.B., Hvelplund, P., Tureček, F.: Dipole-guided electron capture causes abnormal dissociations of phosphorylated pentapeptides. J. Am. Soc. Mass Spectrom. 22, 731-751 (2011)

44. Sugita, Y., Okamoto, Y.: Replica-exchange molecular dynamics method for protein folding. Chem. Phys. Lett. 314, 141-151 (1999)

45. Stewart, J.J.P.: Optimization of parameters for semiempirical methods. $\mathrm{V}$. Modification of NDDO approximations and application to 70 elements. J. Mol. Model. 13, 1173-1213 (2007)

46. Becke, A.D.: New mixing of Hartree-Fock and local density-functional theories. J. Chem. Phys. 98, 1372-1377 (1993)

47. Becke, A.D.: Density functional thermochemistry. III. The role of exact exchange. J. Chem. Phys. 98, 5648-5652 (1993)

48. Yanai, T., Tew, D.P., Handy, N.C.: A new hybrid exchange-correlation functional using the Coulomb-Attenuating Method (CAM-B3LYP). Chem. Phys. Lett. 393, 51-57 (2004)

49. Zhao, Y., Truhlar, D.G.: The M06 suite of density functionals for main group thermochemistry, thermochemical kinetics, noncovalent interactions, excited states, and transition elements: Two new functionals and systematic testing of four M06-class fucntionals and 12 other functionals. Theo. Chem. Acc. 120, 215-241 (2008)

50. Møller, C., Plesset, M.S.: A note on an approximation treatment for many-electron systems. Phys. Rev. 46, 618-622 (1934)

51. Čížek, J., Paldus, J., Šroubková, L.: Cluster expansion analysis for delocalized systems. Int. J. Quantum Chem. 3, 149-167 (1969)

52. Purvis, G.D., Bartlett, R.J.: A full coupled-cluster singles and doubles model. The inclusion of disconnected triples. J. Chem. Phys. 76, 19101918 (1982) 
53. Curtiss, L.A., Raghavachari, K., Pople, J.A.: Gaussian-2 theory using reduced møller-plesset orders. J. Chem. Phys. 98, 1293-1298 (1993)

54. Phillips, J.C., Braun, R., Wang, W., Gumbart, J., Tajkhorshid, E., Villa, E., Chipot, C., Skeel, R.D., Kale, L., Schulten, K.: Scalable molecular dynamics with NAMD. J. Comp. Chem. 26, 1781-1802 (2005)

55. MacKerell Jr., A.D., Bashford, D., Bellott, M., Dunbrack Jr., R.L., Evanseck, J.D., Field, M.J., Fischer, S., Gao, J., Guo, H., Ha, S., Joseph-McCarthy, D., Kuchnir, L., Kuczera, K., Lau, F.T.K., Mattos, C., Michnick, S., Ngo, T., Nguyen, D.T., Prodhom, B., Reiher, W.E.I.I. I., Roux, B., Schlenkrich, M., Smith, J.C., Stote, R., Straub, J., Watanabe, M., Wiorkiewicz-Kuczera, J., Yin, D., Karplus, M.: Allatom empirical potential for molecular modeling and dynamics studies of proteins. J. Phys. Chem. B 102, 3586-3616 (1998)

56. Tureček, F.: Temperature effects in mass spectrometry. On the estimation of thermal energies of organic molecules. Org. Mass Spectrom. 26, 1074-1081 (1991)

57. Tureček, F.: Transient intermediates of chemical reactions by neutralization- reionization mass spectrometry. Top. Curr. Chem. 225, 77-129 (2003)
58. Gilson, T.W., van der Rest, G., Chamot-Rooke, J., Kurlancheek, W., Head-Gordon, M., Jacquenin, D., Frison, G.: Ground electronic state of peptide cation-radicals: A delocalized unpaired electron? J. Phys. Chem. Lett. 2, 1426-1431 (2011)

59. Holm, A.I.S., Hvelplund, P., Kadhane, U., Larsen, M.K., Liu, B., Nielsen, S.B., Panja, S., Pedersen, J.M., Skydstrup, T., Stochkel, K., Williams, E.R., Worm, E.S.: On the mechanism of electron-captureinduced dissociation of peptide dications from $15 \mathrm{~N}$-labeling and crownether complexation. J. Phys. Chem. A 111, 9641-9643 (2007)

60. Tureček, F., Syrstad, E.A.: Mechanism and energetics of intramolecular hydrogen transfer in amide and peptide radicals and cation-radicals. $J$. Am. Chem. Soc. 125, 3353-3369 (2003)

61. Moss, C.L., Isborn, C.M., Li, X.: Ehrenfest dynamics with a timedependent density-functional-theory calculation of lifetimes and resonant widths of charge-transfer states of $\mathrm{Li}+\mathrm{Near}$ an aluminum cluster surface. Phys. Rev. A 80, 024503/1-024503/4 (2009)

62. Chapman, C.T., Liang, W., Li, X.: Ultrafast coherent electron-hole separation dynamics in a fullerene derivative. J. Phys. Chem. Lett. 2, 1189-1192 (2011) 